Syntax Fusion : Jurnal Nasional Indonesia

P-ISSN: $x x x x-x x x x$

e-ISSN : $x x x x-x x x x$

Vol. 1, No. 1, Oktober 2020

\title{
FAKTOR-FAKTOR YANG BERHUBUNGAN DENGAN KEJADIAN PERDARAHAN POST PARTUM DI RSUD INDRAMAYU
}

\section{Rosidah Rosidah, Rica Arieb Shintami, Mitha Erlisya Puspandhani Poltekes Bhakti Pertiwi Husada Cirebon \\ Email.ndakeenar@gmail.com, ricaarieb85@gmail.com, mitham3p@yahoo.com}

Abstrak

Kejadian dalam pendarahan pada post partum di RSUD Indramayu masih cukup tinggi. Hasil observasi terdapat 10 data untuk ibu post partum yang mengalami perdarahan diketahui 2 ibu mengalami preeklamsia, 2 ibu mengalami usia dan 1 ibu berparitas resiko tinggi yaitu grandemultipara. Tujuan pada peenelitian ini ialah untuk mengetahui beberapa faktor yang berhubungan atas kejadian perdarahan pada post partum di RSUD Indramayu.

Jenis dalam sebuah penelitian deskriptif analitik pada pendekatan cross sectional. Hasil penelitiannya adalah ibu post partum di RSUD Indramayu tahun 2019 adalah 10 orang $(11,5 \%)$ positif pre-eklamsia dan 77 orang $(88,5 \%)$ negatif pre-eklamsia; 12 orang $(13,8 \%)$ berumur $<20$ tahun, 62 orang $(71,3 \%)$ berumur $20-35$ tahun dan 13 orang $(14,9 \%)$ berumur $>35$ tahun; 17 orang (13,8\%) primipara, 62 orang (71,3\%) multipara dan 13 orang (14,9\%) grandemultipara; 17 orang $(19,5 \%)$ positif perdarahan post partum dan 70 orang $(80,5 \%)$ negatif tidak perdarahan post partum.

Kesimpulan penelitiannya adalah ada hubungan pre-eklamsia dengan kejadian perdarahan post partum $(p 0,003<\alpha 0,5)$. Ada hubungan umur dengan kejadian perdarahan post partum $(p 0,002<\alpha 0,5)$. Ada hubungan paritas dengan kejadian perdarahan post partum $(p 0,001<\alpha 0,5)$.

Kata Kunci: Pre-eklamsia, Umur, Paritas, Perdarahan Post Partum

\section{Pendahuluan}

Angka Kematian Ibu (AKI) merupakan salah satu indikator untuk melihat keberhasilan upaya kesehatan ibu. AKI adalah rasio kematian, dimana ketika dalam fase kehamilan, persalinan, dan nifas yang menyebabkan pada pengelolaannya memiliki sebab lain seperti halnya pada kecelakaan atau terjatuh pada tiap 100.000 kelahiran dalam hidup. Berdasarkan SDKI tahun 2017 diketahui bahwa AKI mencapai 305 per kelahiran hidup yang disebabkan karna perdarahan 38,24\% (111,2 per 100.000 kelahiran hidup), pre-eklampsia berat $26,47 \%$ (76,97 per 100.000 kelahiran hidup), akibat penyakit bawaan 19,41 (56,44 per 100.000 kelahiran hidup), dan infeksi 5,88\% (17,09 per 100.000 kelahiran hidup) (Kemenkes RI, 2019)

Faktor yang sering disebabkan dalam angka kematian pada ibu bersalin adalah perdarahan post partum (Depkes, 2010). Definisi perdarahan post partum ini yaitu suatu perdarahan yang melebihi dari $500 \mathrm{ml}$ selama 24 jam setelah anak dilahirkan. Perdarahan post partum adalah perdarahan setelah anak lahir melebihi 500ml (Wiknjosastro, 2010). 
Perdarahan biasanya dapat mengakibatkan kehilangan darah pada tubuh wanita lebih dari $500 \mathrm{ml}$ sebelum atau setelah melahirkan (Doengoes, 2011)

Data Dinas Kesehatan Provinsi Jawa Barat (2019) menyebutkan pada tahun 2018 tercatat kurang lebih 900.000 jumlah persalinan dan 100.100 atau $18,9 \%$, sedangkan untuk Kabupaten Indramayu berdasarkan penelitian Tri Wahyuni (2018) terjadi perdarahan pada sekitar 23,4\% atau 150 ibu bersalin dari 5.335 total persalinan. Untuk RSUD Indramayu diketahui jumlah kasus perdarahan post partum periode JanuariDesember 2018 sebanyak 12,4\% atau 88 kasus dari 2.351 persalinan normal. Sedangkan periode Juni-agustus 2019 tercatat dari 650 ibu bersalin sedangkan perdarahan post partumnya $2,6 \%$ atau 19 kasus.

Menurut (I.B.G, 2012) beberapa faktor resiko perdarahan antara lain faktor ibu dan faktor janin. Resiko faktor ibu antara lain umur dan paritas resiko tinggi, jarak kehamilan, anemia, hipertensi, preeklamsia, riwayat kuretase, ketuban pecah dini, partus lama, presipitatus, infeksi, penyakit jantung, atonia uteri, ruptur perineum, retensio plasenta, tertinggalnya plasenta (sisa plasenta), inversio uterus, trauma jalan lahir, penyakit darah, hematoma, persalinan lama, riwayat sc, dan subinvolusi uterus. Sementara faktor janin antara lain kelainan letak janin, janin besar, kehamilan ganda, trauma janin dan lain-lain.

Anggraini, dkk (2016) membuktikan dalam penelitiannya bahwa terdapat sebuah hubungan antara penel atonia uteri, retensio plasenta dan laserasi pada jalan menuju lahiran dengan kejadian perdarahan. Sementara Santriyandari, dkk (2017) membuktikan bahwa ada kaitannya dengan hubungan antara anemia, paritas dan oksitosin trip pada kejadian perdarahan post partum. Penelitian Wardani (2017) juga membuktikan bahwa terdapat suatu hubungan paritas, usia, jarak kehamilan, dan anemia pada perdarahan post partum, dan membuktikan bahwa janin besar dan riwayat secsio cesaria tidak ada sama sekali dengan hubungan ini.

Berdasarkan data yang didapat dari RSUD Indramayu pada tahun 2018 dari 2.351 persalinan spontan terdapat kejadian perdarahan post partum sejumlah 88 kasus. Sedangkan periode Juni-agustus 2019 dari 650 persalinan tercatat kasus perdarahan post partum sebanyak 19 kasus.

Hasil observasi pada 10 data ibu post partum yang mengalami perdarahan diketahui 2 ibu mengalami preeklamsia, 2 ibu berusia risiko tinggi $(<20$ tahun dan $>35$ tahun), serta 1 ibu berparitas grandemultipara,

Persalinan adalah sebuah langkah untuk memproses suatu rangkaian yang berakhir pada hasil konsepsi atas pengeluarannya. Proses ini biasa dimulai ketika sedang kontraksi persalinan, dengan ditandai pada sebuah perubahan progesif saat terjadinya serviks, serta diahkiri oleh kelahiran plasenta (Varney et al., 2007).

Post parfum adalah yang dimulai pada masa setelah lahir dan berakhir ketika alat di kandungannya kembali dalam keadaan sepeti ibu hamil, biasanya hal ini berlangsung selama kurang lebih 6 minggu atau sama dengan 24 hari, namun pada keseluruhannya dapat menjadi pulih selama 3 bulan (Trisnawati,2012)

Perdarahan post partum adalah perdarahan ketika berada pada kalam IV yang lebih dari 500 dalam 24 jam setelah anak dan plasenta dilahirkan (Wiknjosastro, 2010). $500 \mathrm{ml}$ darah akan hilang pada perdarahan ini ketika setelah kelahiran. Perdarahan Post partum diklasifikasikan menjadi 2, yaitu Early Post partum: Terjadi 24 jam pertama setelah bayi lahir, Late Post partum : Terjadi setelah lebih dari 24 jam pertama setelah bayi dilahirkan. 
Frekuensi perdarahan post partum 4/5-15\% dari seluruh persalinan. Berdasarkan penyebabnya : atoni uteri (50-60\%), retensio plasenta (16-17\%), sisa plasenta (23-24\%), pre-eklamsia (7-9\%), laserasi jalan lahir (4-5\%), kelainan darah (0,5-0,8\%).

Pre-eklampsia adalah hipertensi yang timbul setelah 20 minggu kehamilan disertai dengan proteinuria (Prawirohardjo, 2014). Pre-eklampsia adalah suatu penyakit yang menyebabkan tanda-tanda hipertensi, proteinuria dan edema yang dapat timbul ketika hamil. Dalla penyakit ini, pada umumnya dapat terjadi dalam triwulan ke 3 pada masa kehamilan, akan tetapi dapat terjadi pada masa sebelumnya yaitu pada masa mola hidatidosa (I.B.G, 2012).

Penyebab preeclampsia belum diketahui dengan pasti. Meskipun demikian penyakit ini lebih sering ditemukan pada wanita hamil yang primigravida, hiperplasentosis (pada kehamilan kembar, anak besar, dan mola hidatidosa), mempunyai dasar penyakit vascular (hipertensi atau diabetes mellitus), mempunyai riwayat preeklampsia / eklampsia dalam keluarganya.

Jenis-jenis pre-eklampsia terdiri dari pre-eklamsia ringan, berat dan eklamsia. Pre-eklampsia Ringan adalah sebuah timbulan hipertensi yang disertai pada roteinuria dana tau edema setelah usia 20 minggu kehamilan atau setelah kehamilan. Gejala-gejala preeklampsia ringan meliputi (1) kenaikan suhu pada tekanan darak sistol $30 \mathrm{mmHg}$ atau lebih, diastole $15 \mathrm{mmHg}$ atau lebih dari penekanan darah masa kehamilan dan kehamilan 20 minggu atau lebih, sistol $149 \mathrm{mmHg}$ sampai berkurang menjadi $160 \mathrm{mmHg}$, diastole $90 \mathrm{mmHg}$ sampai berkurang menjadi $110 \mathrm{mmHg}$. (2). Proteinuria, secara kuantitatif dapat lebih dari 0,3 gr/liter dalam kurun waktu 24 jam, atau secara kualitatif positif 2 (+2). (3). Edema pada pretibial,dinding abdomen, lumbosacral, wajah atau tangan.

Pre-eklampsia berat ialah preeklampsia dengan tekanan darah sistolik $\geq 160$ $\mathrm{mmHg}$ dan tekanan darah diastolic $\geq 110 \mathrm{mmHg}$ disertai proteinuria lebih $5 \mathrm{~g} / 24$ jam.(Prawirohardjo, 2010). Peningkatan kadar enzim hati dan ikterus, trombosit < $100.000 / \mathrm{mm} 3$ atau penurunan trombosit dengan cepat, Oliguria, yaitu produksi urin $<400$ $\mathrm{ml} / 24$ jam, Proteinuria $>3 \mathrm{gr} /$ liter, Nyeri epigastrium, Nyeri frontal yang berat, Gangguan pengelihatan, Odema pulmonum, Pertumbuhan janin intrauterin yang terhambat, Kenaikan kadar kreatinin plasma (Prawirohardjo, 2010).

Eklampsia adalah kelainan yang paling sering diterima oleh wanita hamil, dalam persalinan atau pada masa nifas yang selalu ditandai dengan timbulnya penyakit kejangkejang (tidak timbul akibat kelainan neurologik) dan atau koma dimana pada sebelumnya sudah terjadi gejala preeklamp-sia (Erlina, 2014). Gejala dan tanda-tanda eklampsia pada umumnya kejang yang didahului dengan semakin parahnya preeklampsia dan mulai terjadinya nyeri kepala didaerah frontal, gangguan pengelihatan, mual, nyeri di epigastrium, dan hiperrefleksia.

Ibu hamil dapat mengalami sebuah preeklampsia yang beresiko 1.5 kali lipat terkena perdarahan postpartum hal ini kemungkinan karena patogenesis yang multifaktorial, diantaranya faktor angiogenik, disfungsi endothelial, dan gangguan darah uteroplasental yang dapat menyebabkan hipertensi dan abnormalitas koagulasi. Pada ibu yang terkena preeklampsia terjadi berbagai perubahan pada tubuhnya seperti perubahan keseimbangan prostaglandin yang menyebabkan peningkatan tromboksan sehingga dapat menyebabkan kerusakan pembuluh darah dan memudahkan trombosit untuk mengadakan suatu agrasi dan adhesi yang akhirnya mempersempit lumen yang menyebabkan gangguan pada aliran darah. Upaya mengatasi timbunan trombosit ini terjadi lisis yang mengakibatkan turunnya trombosit darah serta dengan mudah menyebabkan perdarahan (I.B.G, 2012). 
Umur adalah jenjang masa sejak tanggal dilahirkan sampai meninggal dalam hitungan tahun (Djamhoer, 2010). Dengan kurun waktu pada saat reproduksi sehat dikenal pada usia yang aman untuk masa kehamilan dan persalinan adalah 20-30 tahun. Kematian materian pada wanita hamil yang melahirakan pada masa usia dibawah 20 tahun ternyata 2-5 kali lebih tinggi daripada kematian pada usia 20-19 tahun. Dan kembali meningkat pada usia 30-35 tahun (Wiknjosastro, 2010).

Wanita yang melahirkan pada usia 20 tahun atau lebih dari 35 tahun merupakan salah satu faktor yang beresiko terjadinya perdarahan pasca persalinan yang mengakibatkan kematial material. Karena pada hal ini dengan usia dibawah 20 tahun yaitu pada fungsi reproduksinya belum berkembang dengan sempurna, sedangkan pada usia diatas 35 tahun mengalami penurunan fungsi reproduksi seorang wanita dibandingkan dengan fungsi reproduksi normal, sehingga memungkinkan terjadinya komplikasi pasca persalinan dengan diutamakan perdarahan yang lebih besar (Djamhoer, 2010).

Menurut penelitian Pardosi (2010), bahwa pada masa peningkatan dalam kepercayaan yaitu 95\% seorang ibu yang berumur dibawah 20 atau diatas 30 tahun dapat memiliki resiko perdarahan post partum dengan 3,3 lebih bear disbanding dengan ibu yang berumur 20 sampai 29 tahun. Selain itu penelitian Najah (2010) menyatakan bahwasanya peningkatan kepercayaan mencapai 95\% umur ibu dibawah 20 tahun dan diatas 35 tahun yang bermakna sebagai faktor resiko yang dapat memengaruhi perdarahan post partum.

Paritas berasal dari bahasa Latin, pario, yang berarti menghasilkan. Secara umum, paritas didefinisikan sebagai tanda dalam melahirkan dengan keadaan anak dengan keadaan baik (hidup) atau dengan keadaan yang kurang baik (meninggal), tetapi bukan dengan aborsi, tanpa melihat jumlah anak. Dengan demikian, kelahiran anak kembar hanya dapat dihitung satu kali paritas (Stedman, 1998 dalam Varney, 2013). Para adalah jumlah pada kehamilan yang berakhir dengan kelahiran bayi atau bayi yang mampu bertahan hidup. Titik ini dapat dicapai ppada usia kehamilan 20 minggu dengan berat janin 500 gram (Varney et al., 2007).

Jumlah paritas merupakan komponen dari alah satu status paritas yang sering ditulis dengan notasi G-P-Ab, dimana "G" menyatakan jumlah kehamilan (gestasi),"P" menyatakan jumlah paritas, dan "Ab" menyatakan jumlah abortus. Sebagai contoh, seorang wanita dengan status paritas G3P1Ab1, berarti wanita tersebut pernah mengandung sebanyak dua kali, dengan sekali paritas dan sekali abortus, yang saat ini tengah mengandung untuk ketiga kalinya.

Berdasarkan sebuah jumlah, maka paritas dapat dibedakan menjadi : Nulipara (wanita yang belum merasakan hamil sama sekali), Primipara (wanita yang telah melahirkan satu kali), Multipara (wanita yang melahirkan 2-4 kali) dan Grandemultipara (wanita yang sudah melahirkan sebanyak 5 atau lebih).

Dalam persalinan pada pembuluh darah yang terdapat uterus untuk meningkatkan sirkulasi, atoni uteri dan subinvolusi uterus yang mengakibatkan kontraksi uterus menurun dan dapat mengakibatkan pembuluh darah melebar serta tidak dapat menutup dengan sempurna yang mengakibatkan perdarahan terjadi terus menerus

\section{Metode Penelitian}

Jenis penelitian ini merupakan penelitian deskriptik analitik dengan pendekatan cross sectional. Populasi dalam penelitian ini adalah seluruh ibu post partum yang bersalin normal di Ruang VK RSUD Indramayu periode Juni-Agustus yang berjumlah 
650 orang dengan jumlah sampelnya 87 orang. Instrumen penelitian berupa lembar ceklist. Analisis data menggunaka uji Chi Square.

\section{Hasil dan Pembahasan}

a. Pre-eklamsia Pada Ibu Post Partum di RSUD Indramayu

Gambaran pre-eklamsia saat kehamilan pada ibu post partum di RSUD Indramayu adalah sebagai berikut :

Tabel 1

Distribusi Frekuensi Pre-eklamsia Ibu post partum

di RSUD Indramayu

\begin{tabular}{|c|c|c|c|}
\hline No. & $\begin{array}{l}\text { Pre-eklamsia } \\
\text { Ibu }\end{array}$ & $\mathrm{F}$ & $\%$ \\
\hline 1. & Positif & 10 & 11,5 \\
\hline 2. & Negatif & 77 & 88,5 \\
\hline & Total & 87 & 100,0 \\
\hline
\end{tabular}

Berdasarkan data tabel di atas dapat dilihat bahwa ibu post partum di RSUD Indramayu yang menjadi responden penelitian faktor-faktor yang berhubungan dengan kejadian perdarahan post partum di RSUD Indramayu adalah 11,5\% mengalami preeklamsia selama kehamilannya dan $88,5 \%$ tidak pre-eklamsia.

b. Umur Ibu post partum di RSUD Indramayu

Gambaran umur ibu post partum di RSUD Indramayu adalah sebagai berikut :

Tabel 2

Distribusi Frekuensi Umur Ibu post partum di RSUD Indramayu

\begin{tabular}{cccc}
\hline No. & Umur Ibu & F & $\%$ \\
\hline 1. & $<20$ Tahun & 12 & 13,8 \\
2. & $20-35$ Tahun & 62 & 71,3 \\
3. & $>35$ Tahun & 13 & 14,9 \\
\hline & Total & 87 & 100,0 \\
\hline
\end{tabular}

Berdasarkan data tabel di atas dapat dilihat bahwa ibu post partum di RSUD Indramayu yang menjadi seuatu responden penelitian dalam faktor yang berhubungan dengan kejadian perdarahan post partum di RSUD Indramayu adalah 13,8\% berumur < 20 Tahun, 71,3\% berumur 20-35 tahun dan 14,9\% berumur $>35$ tahun.

c. Paritas Ibu post partum di RSUD Indramayu

Gambaran paritas ibu post partum di RSUD Indramayu adalah sebagai berikut :

Tabel 3

Distribusi Frekuensi Paritas Ibu post partum

di RSUD Indramayu

\begin{tabular}{ll}
\hline No. & Paritas Ibu \\
\hline
\end{tabular}




\begin{tabular}{rccc}
\hline 1. & Primipara & 12 & 13,8 \\
2. & Multipara & 62 & 71,3 \\
3. & Grandemultipara & 13 & 14,9 \\
\hline & Total & 87 & 100,0 \\
\hline
\end{tabular}

Berdasarkan data tabel diatas dapat dilihat bahwa ibu post partum di RSUD Indramayu yang menjadi seuatu responden penelitian dalam faktor yang berhubungan dengan kejadian perdarahan post partum di RSUD Indramayu adalah $13,8 \%$ primipara (1 anak), 71,3\% multipara (2-3 anak) dan 14,9\% grandemultipara (4 anak lebih)

\section{d. Kejadian Perdarahan Post Partum di RSUD Indramayu}

Gambaran kejadian perdarahan post partum di RSUD Indramayu adalah sebagai berikut :

Tabel 4

Distribusi Frekuensi Kejadian Perdarahan Post partum di RSUD Indramayu

\begin{tabular}{cccc}
\hline No. & $\begin{array}{c}\text { Perdarahan Post } \\
\text { Partum }\end{array}$ & F & $\%$ \\
\hline 1. & Positif & 17 & 19,5 \\
2. & Negatif & 70 & 80,5 \\
\hline & Total & 87 & 100,0 \\
\hline
\end{tabular}

Berdasarkan data tabel diatas dapat dilihat bahwa ibu post partum di RSUD Indramayu yang menjadi seuatu responden penelitian dalam faktor yang berhubungan dengan kejadian perdarahan post partum di RSUD Indramayu tahun adalah 19,5\% mengalami perdarahan post partum dan $80,5 \%$ tidak mengalami perdarahan post partum.

\section{e. Hubungan Pre-eklamsia dengan Kejadian Perdarahan Post Partum di RSUD Indramayu}

Tabel 5. Hasil Analisis Chi Square hubungan pre-eklamsia dengan kejadian perdarahan post partum di RSUD Indramayu

\begin{tabular}{|c|c|c|c|c|c|c|}
\hline \multirow{3}{*}{ Pre-eklamsia } & \multicolumn{6}{|c|}{ Perdarahan Post Partum } \\
\hline & \multicolumn{2}{|c|}{ Positif } & \multicolumn{2}{|c|}{ Negatif } & \multicolumn{2}{|c|}{ Total } \\
\hline & $\mathrm{N}$ & $\%$ & $\mathrm{~N}$ & $\%$ & $\mathrm{~N}$ & $\%$ \\
\hline Positif & 8 & 80,0 & 2 & 20,0 & 10 & 100,0 \\
\hline Negatif & 9 & 11,7 & 68 & 88,3 & 77 & 100,0 \\
\hline Total & 17 & 19,5 & 70 & 80,5 & 87 & 100,0 \\
\hline \multicolumn{7}{|c|}{$\chi^{2}=26,270$} \\
\hline
\end{tabular}

Hasil analisis bivariat hubungan pre-eklamsia dengan kejadian perdarahan post partum di RSUD Indramayu dengan uji Chi Square adalah diketahui bahwa hasil uji bivariat hubungan pre-eklamsia dengan kejadian perdarahan post partum di RSUD Indramayu dengan Chi Square mendapatkan nilai $p$ 0,003. Karena nilai $p$ 0,003 < nilai 
alpha ( $\alpha$ ) 0,05 maka berarti Ho ditolak dan Ha diterima. Artinya terbukti bahwa ada hubungan signifikan pre-eklamsia dengan kejadian perdarahan post partum di RSUD Indramayu.

Secara deskriptif hubungan signifikan antara pre-eklamsia dengan kejadian perdarahan post partum di RSUD Indramayu dapat terlihat dari data tabulasi di atas yang menunjukkan bahwa ibu post partum yang waktu kehamilan dan bersalinnya mengalami pre-eklamsia sebagian besar $(80,0 \%)$ mengalami kejadian perdarahan post partum. Sementara ibu post partum yang waktu kehamilan dan bersalinnya tidak mengalami preeklamsia hanya $11,7 \%$ yang mengalami kejadian perdarahan post partum.

\section{f. Hubungan Umur dengan Kejadian Perdarahan Post Partum di RSUD Indramayu}

Tabel 5.8

Hasil Analisis Chi Square hubungan umur dengan kejadian perdarahan post partum di RSUD Indramayu

\begin{tabular}{|c|c|c|c|c|c|c|}
\hline \multirow{2}{*}{ Umur } & \multicolumn{6}{|c|}{ Perdarahan Post Partum } \\
\cline { 2 - 7 } & \multicolumn{2}{|c|}{ Positif } & \multicolumn{2}{c|}{ Negatif } & \multicolumn{2}{c|}{ Total } \\
\cline { 2 - 7 } & $\mathrm{N}$ & $\%$ & $\mathrm{~N}$ & $\%$ & $\mathrm{~N}$ & $\%$ \\
\hline$<20$ Tahun & 6 & 50,0 & 6 & 50,0 & 12 & 100,0 \\
\hline $20-35$ Tahun & 0 & 0,0 & 62 & 100,0 & 62 & 100,0 \\
\hline$>35$ Tahun & 11 & 84,6 & 2 & 15,4 & 13 & 100,0 \\
\hline Total & 17 & 19,5 & 70 & 80,5 & 87 & 100,0 \\
\hline \multicolumn{7}{|c|}{$\chi^{2}=57,155$} \\
\hline
\end{tabular}

Hasil analisis bivariat hubungan umur dengan kejadian perdarahan post partum di RSUD Indramayu dengan uji Chi Square adalah diketahui bahwa hasil uji bivariat hubungan umur dengan kejadian perdarahan post partum di RSUD Indramayu dengan Chi Square mendapatkan nilai p 0,002. Karena nilai p 0,002< nilai alpha $(\alpha) 0,05$ maka berarti Ho ditolak dan Ha diterima. Artinya terbukti bahwa ada hubungan signifikan umur dengan kejadian perdarahan post partum di RSUD Indramayu .

Secara deskriptif hubungan signifikan antara umur dengan kejadian perdarahan post partum di RSUD Indramayu dapat terlihat dari data tabulasi di atas yang menunjukkan bahwa ibu post partum yang berumur $<20$ tahun separuhnya $(50,0 \%)$ mengalami kejadian perdarahan post partum. Sementara ibu post partum yang berumur 20-35 tahun tidak ada $(0,0 \%)$ yang mengalami kejadian perdarahan post partum. Sedangkan ibu post partum yang berumur $>35$ sebagian besar $(84,6 \%)$ mengalami kejadian perdarahan post partum. Data tersebut memperlihatkan bahwa umur risiko tinggi ( $<20$ tahun dan $>35$ tahun) merupakan faktor risiko terjadinya perdarahan post partum.

\section{g. Hubungan Paritas dengan Kejadian Perdarahan Post Partum di RSUD Indramayu}

Tabel 5.9

Hasil Analisis Chi Square hubungan paritas dengan kejadian perdarahan pospartumdi

RSUD Indramayu 


\begin{tabular}{|c|c|c|c|c|c|c|}
\hline \multirow{2}{*}{ Paritas } & \multicolumn{6}{|c|}{ Perdarahan Post Partum } \\
\cline { 2 - 7 } & \multicolumn{2}{|c|}{ Positif } & \multicolumn{2}{c|}{ Negatif } & \multicolumn{2}{c|}{ Total } \\
\cline { 2 - 7 } & $\mathrm{N}$ & $\%$ & $\mathrm{~N}$ & $\%$ & $\mathrm{~N}$ & $\%$ \\
\hline Primipara & 6 & 50,0 & 6 & 50,0 & 12 & 100,0 \\
\hline Multipara & 0 & 0,0 & 62 & 100,0 & 62 & 100,0 \\
\hline Grandemultipara & 11 & 84,6 & 2 & 15,4 & 13 & 100,0 \\
\hline Total & 17 & 19,5 & 70 & 80,5 & 87 & 100,0 \\
\hline & $\chi^{2}=50,233$ & \multicolumn{6}{c}{-value $=0,001$} \\
\hline
\end{tabular}

Hasil analisis bivariat hubungan paritas dengan kejadian perdarahan post partum di RSUD Indramayu dengan uji Chi Square adalah diketahui bahwa hasil uji bivariat hubungan paritas dengan kejadian perdarahan post partum di RSUD Indramayu dengan Chi Square mendapatkan nilai p 0,001. Karena nilai p 0,001 < nilai alpha $(\alpha) 0,05$ maka berarti Ho ditolak dan Ha diterima. Artinya terbukti bahwa ada hubungan signifikan paritas dengan kejadian perdarahan post partum di RSUD Indramayu .

Secara deskriptif hubungan signifikan antara paritas dengan kejadian perdarahan post partum di RSUD Indramayu dapat terlihat dari data tabulasi di atas yang menunjukkan bahwa ibu post partum yang berparitas primipara, separuhnya $(50,0 \%)$ mengalami kejadian perdarahan post partum. Sementara ibu post partum yang berparitas multipara tidak ada $(0,0 \%)$ yang mengalami kejadian perdarahan post partum. Sedangkan ibu post partum yang berparitas $>35$ sebagian besar $(84,6 \%)$ mengalami kejadian perdarahan post partum. Data tersebut memperlihatkan bahwa paritas risiko tinggi (primipara dan grandemultipara) merupakan faktor risiko terjadinya perdarahan post partum.

Hasil penelitian menunjukkan bahwa ibu post partum di RSUD Indramayu yang menjadi responden penelitian faktor-faktor yang berhubungan dengan kejadian perdarahan post partum di RSUD Indramayu adalah 11,5\% mengalami pre-eklamsia selama kehamilannya dan $88,5 \%$ tidak pre-eklamsia; $13,8 \%$ berumur $<20$ Tahun, $71,3 \%$ berumur 20-35 tahun dan 14,9\% berumur $>35$ tahun; 13,6\% primipara ( 1 anak), 75,0\% multipara (2-3 anak) dan 11,4\% grandemultipara (4 anak lebih); 19,5\% mengalami perdarahan post partum dan $80,5 \%$ tidak mengalami perdarahan post partum.

Hasil analisis bivariat hubungan pre-eklamsia dengan kejadian perdarahan post partum di RSUD Indramayu dengan uji Chi Square mendapatkan nilai p 0,003. Karena nilai p 0,003 < nilai alpha $(\alpha) 0,05$ maka berarti Ho ditolak dan Ha diterima. Artinya terbukti bahwa ada hubungan signifikan pre-eklamsia dengan kejadian perdarahan post partum di RSUD Indramayu .

Ibu hamil yang mengalami preeklampsia beresiko terkena perdarahan postpartum hal ini kemungkinan karena patogenesis yang multifaktorial, diantaranya faktor angiogenik, disfungsi endothelial, dan gangguan darah uteroplasental yang dapat menyebabkan hipertensi dan abnormalitas koagulasi. Pada ibu yang terkena preeklampsia terjadi berbagai perubahan pada tubuhnya seperti perubahan keseimbangan prostaglandin yang menyebabkan peningkatan tromboksan sehingga dapat menyebabkan kerusakan pembuluh darah dapat dengan mudah suatu trombosit mengadakan agregasi dan adhesi sehingga memppersempit lumen dan makin menganggu ke sebuah aliran darah organ vital. Upaya mengatasi timbunan trombosit ini terjadi lisis, sehingga jumlah trombosit 
darah dapat turun serta memudahan perdarahan (I.B.G, 2012). Selain itu, preeklamasi pada ibu juga dapat mempercepat hemolisis.

Hasil analisis bivariate dengan hubungan umur dengan menjadikan pendarahan post partum di RSUD Indramayu dengan sebuah uji Chi Square yang mendapatkan nilai 0,002. Karena nilai p 0,002 < nilai alpha $(\alpha) 0,05$ maka berarti Ho ditolak dan Ha diterima. Artinya terbukti bahwa ada hubungan signifikan umur dengan kejadian perdarahan post partum di RSUD Indramayu .

Hasil penelitian ini sesuai dengan teori (Wiknjosastro, 2010) yang menyatakan bahwa perdarahan post partum lebih sering terjadi pada ibu yang berumur risiko tinggi ( $<20$ tahun dan $>35$ tahun). Hal ini terjadi karena pada ibu yang berumur muda $<20$ tahun secara fisik dan psikis belum siap menjadi ibu sehingga sering mengalami partus lama yang dapat menimbulkan perdarahan. Sementara pada ibu yang berumur tua $>35$ tahun sudah terjadi penurunan dan pelamahan fisik terutaam organ-organ reproduksinya sering mengalami kelemahan atau kurang kuatnya otot uterus yang dapat menyebabkan berbagai kejadian pemicu perdarahan post partum.

Hasil penelitian ini juga sama dengan hasil penelitian Wastinah (2009) yang meneliti tentang faktor-faktor ibu yang berhubungan dengan kejadian perdarahan postpartum primer. Wastinah menyimpulkan bahwa faktor ibu berupa umur memberikan pengaruh positif, kuat dan signifikan terhadap kejadian perdarahan postpartum primer.

Hasil penelitian ini sesuai dengan hasil penelitian Sudarmi Masrifah (2009) tentang faktor-faktor yang mempengaruhi kejadian perdarahan post partum di Cimahi tahun 2009 yang salah satu kesimpulannya menyatakan bahwa faktor umurs ibu merupakan salah satu faktor yang mempengaruhi kejadian perdarahan post partum dengan p-value 0,001 .

Wanita yang melahirkan pada usia dibawah 20 tahun atau lebih dari 35 tahun merupakan salah satu actor terjadinya perdarahan pasca persalinan yang dapat mengakibatkan kematian material. Hal ini dikarenakan usia dibawah 20 tahun belum berkembang pada fungsi reproduksinya dengan sempurna, sedangkan usia yang menginjak umur 35 tahun keatas alat reproduksi seorang wanita sudah mengalami penurunan untuk dibandingkan dengan fungsi reproduksi normal, sehingga kemungkinan terjadinya terjadinya komplikasi akan lebih besar.

Hasil analisis bivariat dengan hubungan paritas pada kejadian perdarahan dengan uji Chi Sqeare mendapatkan nilai p 0,001. Karena nilai p $0,001<$ nilai alpha $(\alpha) 0,05$ maka berarti Ho ditolak dan Ha diterima. Artinya terbukti bahwa ada hubungan signifikan paritas dengan kejadian perdarahan post partum di RSUD Indramayu .

Hasil penelitian ini sama dengan hasil penelitian Wastinah (2009) yang meneliti tentang faktor pada kejadian perdarahan postpartum primer. Wastinah menyimpulkan bahwa faktor ibu berupa paritas memberikan pengaruh positif, kuat dan signifikan terhadap kejadian perdarahan postpartum primer.

Hasil penelitian yang sesuai dengan teori (Wiknjosastro, 2010) yang menyatakan bahwa perdarahan post partum sangat lebih sering terjadinya pada seorang ibu yang berparitas grandemultipara dan primipara. Hal ini terjadi karena pada ibu yang berparitas grandemultipara sering mengalami kelemahan atau kurang kuatnya otot uterus yang dapat menyebabkan berbagai kejadian pemicu perdarahan post partum. Sementara pada primipara sering persalinan menyebabkan robekan jalan lahir yang berpotensi mengalami perdarahan.

Hasil penelitian ini sesuai dengan hasil penelitian Sudarmi Masrifah (2009) tentang faktor-faktor yang mempengaruhi kejadian perdarahan post partum di Cimahi 
tahun 2009 yang salah satu kesimpulannya menyatakan bahwa faktor paritas ibu merupakan salah satu faktor yang mempengaruhi kejadian perdarahan post partum dengan p-value 0,003 .

Ibu dengan paritas tinggi, terutama primipara dan grandemultipara, seringkali disebut sebagai faktor risiko yang penting pada kejadian perdarahan postpartum. Perdarahan postpartum pada grandemultipara terjadi akibat otot pada rahim sudah tidak mampu berkontraksi dengan baik apabila terlalu ingin mempunyai anak banyak, maka otot rahim akan semakin melemah.

\section{Kesimpulan}

Berdasarkan hasil penelitian didapatkan bahwa terdapat hubungan pre-eklamsia dengan kejadian perdarahan post partum di RSUD Indramayu dengan nilai p 0,003, terdapat hubungan umur dengan kejadian perdarahan post partum di RSUD Indramayu dengan nilai $\mathrm{p} 0,002$, terdapat hubungan paritas dengan kejadian perdarahan post partum di RSUD Indramayu dengan nilai p 0,001. Dari hasil tersebut diharapkan responden dapat merencanakan kehamilan lebih memperhatikan jumlah paritas dan jika paritas resiko terjadinya perdarahan post partum maka hendaknya selalu rajin konsultasi ke bidan atau dokter sesuai jadwal yang dianjurkan. Tenaga kesehatan pun hendaknya lebih aktif lagi memberikan informasi tentang bahaya perdarahan post partum pada setiap ibu post partum dan memberikan konseling agar ibu post partum dapat terhindar dari perdarahan post partum.

\section{Bibliografi}

Depkes RI, 2009, Asuhan Persalinan Normal, Jakarta

Depkes RI, 2010, Panduan Materi Kelas Ibu Hamil, Jakarta : Depkes

Kemenkes RI. (2019). Profil Kesehatan Indonesia 2018. Kementerian Kesehatan RI Dinkes Jabar, 2019, Profil Kesehatan Jawa Barat Tahun 2018.

Dinkes Indramayu, 2019, Profil Kesehatan Kabupaten Indramayu Tahun 2018.

Dwi Asri, 2010, Asuhan Kehamilan, Yogyakarta : Numed

Djamhoer. (2010). Buku Ajar Persalinan.

Doengoes, M. E. (2011). Ilmu Kebidanan.Badriah,2009.Metodologi Penelitian Kesehatan, Bandung;Multazam

I.B.G, M. (2012). Kapita Selekta Penatalaksanaan Rutin Obstetri Ginekologi dan Keluarga Berencana

Rukiyah, 2010.Dukungan Suami Terhadap Lama Persalinan Kala 1 dan 2 Pada Primigravida di RSUD Kota Surakarta.Surakarta

Hanifa, .2013.Kapita Selekta Kedokteran.Jakarta: EGC

Manuaba, IBG.2012.Kapita Selekta Penatalaksanaan Rutin Obstetri Ginekologi dan Keluarga Berencana.Jakarta: EGC

Mochtar, Rustam.2014.Sinopsis Obstetri.Jakarta: EGC

Jung, 2013, National Commission to Prevent Infant Mortality, Jakarta : Gramedia

Sudiyana, 2012, Bahaya Preeklamsia dalam Kehamilan, Jakarta : Nuha Medika

Notoatmodjo, S.2010.Metodologi Penelitian Kesehatan.Jakarta: Rineka Cipta

Sarwono, Prawirohardjo, 2014. Buku Pelayanan Kesehatan Maternal dan Neonatal. Jakarta: Yayasan Bina Pustaka

Prawirohardjo, 2010. Ilmu Kandungan. Jakarta: Yayasan Bina Pustaka 
Faktor-Faktor Yang Berhubungan Dengan Kejadian Perdarahan Post Partum

Erlina, 2014. Obstetric and Ginecology.Jakarta: Hipocrates

Saifuddin, Abdul Bari.2012.Buku Acuan Pelayanan Kesehatan Maternal dan Neonatal.Jakarta: YBPSP

Sulaiman, 2010, Asuhan Persalinan dengan Penyulit, Jakarta : EGC

Varney, H., Kriebs, J. M., \& Gegor, C. L. (2007). Buku ajar asuhan kebidanan. Jakarta: Egc, 672-788.

Wiknjosastro, Hanifa,2010.Ilmu Kandungan.Jakarta: Yayasan Bina Pustaka

Marylin E. Dongoes, 2011,.Ilmu Kebidanan.Jakarta: EGC 